\title{
GPPS-CH-2020-0148
}

\section{Assessment of the performance boundaries of very low specific thrust direct-drive turbofan engines at aircraft level for EIS 2025}

\author{
Sajal Kissoon \\ Propulsion Engineering Centre, School of \\ Aerospace, Transport and Manufacturing \\ Cranfield University \\ s.kissoon@cranfield.ac.uk \\ Bedford, United Kingdom
}

\author{
Fan Zhang \\ Hunan Aviation Powerplant Research Institute \\ Oscarzhang0421@outlook.com \\ HAPRI, zhuzhou 412002, China
}

\author{
Christos Mourouzidis \\ Propulsion Engineering \\ Centre, School of Aerospace, \\ Transport and Manufacturing \\ Cranfield University \\ c.mourouzidis@cranfield.ac.uk \\ Bedford, United Kingdom
}

\author{
loannis Roumeliotis \\ Propulsion Engineering \\ Centre, School of Aerospace, \\ Transport and Manufacturing \\ Cranfield University \\ I.Roumeliotis@cranfield.ac.uk \\ Bedford, United Kingdom
}

\author{
Vassilios Pachidis \\ Propulsion Engineering \\ Centre, School of Aerospace, \\ Transport and Manufacturing \\ Cranfield University \\ v.pachidis@cranfield.ac.uk \\ Bedford, United Kingdom
}

\section{ABSTRACT}

Within the past decade, concerns over the environmental impact of civil aviation have pushed the research community towards the development of more efficient propulsion technology, which delivers a lower carbon and NOx footprint. The current progress achieved in the various specialised disciplines creates the need to redefine the performance barrier achievable by 2025 state-of-the-art aero-engines. This paper summarises some of the latest advancements within the gas turbine research community on the performance modelling and analysis of very low dspecific thrust direct-drive turbofan engines for EIS 2025. Engine and aircraft performance models were used to predict the extent of fuel burn reduction at aircraft level that could be achieved by reducing the engine specific thrust level, increasing operating pressure and temperature levels and applying technology factors representing a step beyond current state-of-the-art. The models represented modern three-spool direct-drive turbofans powering a typical A350XWB-type aircraft. The outputs of the engine design of experiments (DoE) exercise resulted in three most promising candidates. Targeting EIS in 2025, the final optimum design showed $14.81 \%$ block fuel improvement for a representative long $(7000 \mathrm{~nm})$ range mission, accompanied by $30.9 \%$ penalty on engine weight. These results propose that with current technology level, at the lower end of the specific thrust range, there is still available design space for the direct-drive turbofan architecture.

\section{INTRODUCTION}

In order to achieve and maintain a leadership position within the aerospace sector, engine manufacturers are continuously in pursuit of more efficient engines in a commercial environment where even an improvement of $0.1 \%$ in terms of SFC is considered by airlines to be of significant benefit in the long-run (Pitt and Norsworthy, 1999). Additionally, with the aerospace sector under scrutiny due to its contribution to GHG emissions, the Advisory Council for Aviation Research and Innovation in Europe (ACARE) put forward its 'vision' for 2020 (European Commission, 2001) setting a target of $50 \%$ reduction in fuel-burn and perceived noise, and $80 \%$ reduction in landing/take-off NOx emission compared to a typical EIS in 2000 aircraft. This further restricts the design space of the conventional engine architecture which is already at its limit in terms of efficiency.

The overall efficiency of an engine is a product of the propulsive, thermal and transfer efficiency. Thermal efficiency depends on component efficiencies, overall pressure ratio (OPR) and turbine entry temperature (TET) which in turn depends on advancements in material. Propulsive efficiency dictates how well useful work is achieved by the propulsive jets relative to their kinetic energy. With higher jet velocity, with respect to the airspeed, propulsive efficiency decreases. This has led to the development of high by-pass ratio turbofan engines which led to large fan diameters and weight implications due to the size of the fan and the nacelle. Transfer efficiency dictates the extent of which the energy supplied by the core reaches the 
bypass stream flow. High specific thrust engines have higher transfer efficiencies than their counterpart. However, the decrease in transfer efficiency is comparatively low compared to the gain in propulsive efficiency (Rolt and Whurr, 2015). This is one of the reasons recent research focused on achieving very low specific thrust such as the VITAL project (Korsia, 2009) which studied unconventional engine configurations such as the large direct-drive turbofan, the contra-rotating turbofan and the geared turbofan.

Recent developments in materials and aerodynamic design have pushed the performance boundaries and enabled further exploration of the design space. This paper explores the potential for improvement of a three shaft engine through the design of engine where the main design parameters were the specific thrust, which specifies the BPR, OPR, TET and FPR and by taking into consideration the weight and cooling requirements. The initial step was the establishment of technological limiters which define the design space and set the limits for the engine design process. The engine performance was simulated using NPSS and through a parametric optimisation process, an optimum set of engines were obtained which minimises SFC while reaching the net thrust target. Using a representative long range aircraft model, a mission analysis was performed to obtain the block fuel burn and NOx emissions for a typical mission profile. Subsequently, it was compared to 2010 EIS baseline engine to establish the performance capability of a very low specific thrust direct-drive turbofan engine at aircraft level for EIS 2025 .

\section{TURBOFAN ENGINE DESIGN}

An overview of the general methodology is illustrated in Figure 1 . The engine design was restricted by technological limitations, which defined the design space, and by flight mission.

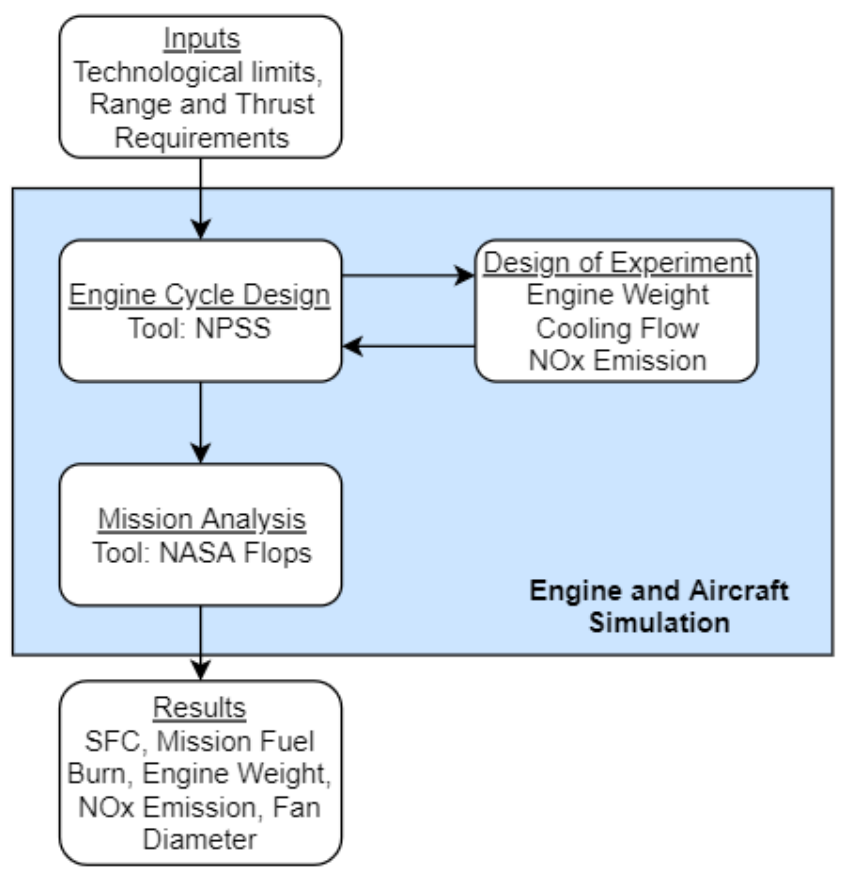

Figure 1 Overview of Methodology

\section{Design Constraints}

The design space is restricted to the modelling of a high BPR turbofan engine with technological limiters set to an engine with EIS by 2025 . The engine limitations are show in Table 1.

Table 1: Engine Design Constraints

\begin{tabular}{l|l}
\hline \hline Limitations & \\
\hline \hline $\operatorname{Max}_{3}(\mathrm{~K})$ & 1000 \\
\hline $\operatorname{Max}_{4}(\mathrm{~K})$ & 1973 \\
\hline $\operatorname{Max}$ Fan & 3.90 \\
Diameter (m) & \\
\hline $\begin{array}{l}\text { Min Fan Hub } \\
\text { to Tip Ratio }\end{array}$ & 0.25 \\
\hline \hline
\end{tabular}

The choice of the OPR is dictated by the maximum blade and disk metal temperature at the HPC exit $\left(\mathrm{T}_{3}\right)$ and to what extent the thermal efficiency is affected due to the decrease in compressor efficiency (Sauer et al., 2019). The latter is mainly due to the increase in air density which tends to reduce the size of the blades and magnifies the effects of losses such as tip clearance. The maximum HPC exit temperature in this case was set to $1000 \mathrm{~K}$ which is indicative of the next generation compressors (Lagow, 2016) and is based on advanced nickel superalloys which are less susceptive to oxidation and/or creep compared to titanium alloys.

The TET was restricted to $1973 \mathrm{~K}$ which was achieved through a combined effect of the advancements made in casting of nickel alloys into a single crystal structure which increases the blade's resistance to mechanical loads at high temperature, thermal barrier ceramic coating which adds an extra capability to sustain an extra $100 \mathrm{~K}$ more and film cooling which forms a protective barrier against the hot gas entering the turbine. (Livingood et al., 1971).

Although the BPR does not have an upper limit which can be quantitatively stated, it is limited by how effectively power can be extracted from the core without affecting the thermal and transfer efficiency at the expense of propulsive efficiency. Additionally, for a fixed core, increasing BPR, increases the fan diameter which is restricted by the distance between the wing and ground clearance requirements. On the other hand, fixing the fan diameter results in core size reduction, which is limited by cooling requirements.

Due to recent progress achieved by Pratt and Whitney in 2017, the fan hub to tip ratio technological limit which was initially thought of to be 0.3 (Walsh and Fletcher, 2004) was recently set to be 0.25 or less (Heikurinen and Townsend, 2017). This was achieved by a unique design which allows the fan blades to be integrally formed with the rotor hub. In order to take into account this improvement in technology, the hub to tip ratio of the baseline engine was set to 0.3 while that of the engine models were set to 0.25 .

Advancements made in reducing the size and thickness of the nacelle is advantageous to enable greater fan diameters to be achieved without impinging upon ground clearance requirements. This also has noise reduction benefits. Depending on the number of parts that are present within the 
nacelle (e.g. presence of a gearbox would tend to increase the fan cowl length), for a direct drive engine, progress achieved by Safran in the development of the Pearl 700 nacelle which is able to "incorporate a larger-diameter fan in the nacelle's ultra-slim aero lines" (Safran, 2020) gives a clear indication of the rate of progress achieved in nacelle development.

\section{Engine Design}

A three-shaft, directly driven, turbofan engine model was built using the engine performance software, NPSS (Numerical Propulsion System Simulation) which supports design, off-design and transient performance calculations (SWRI, 2016).

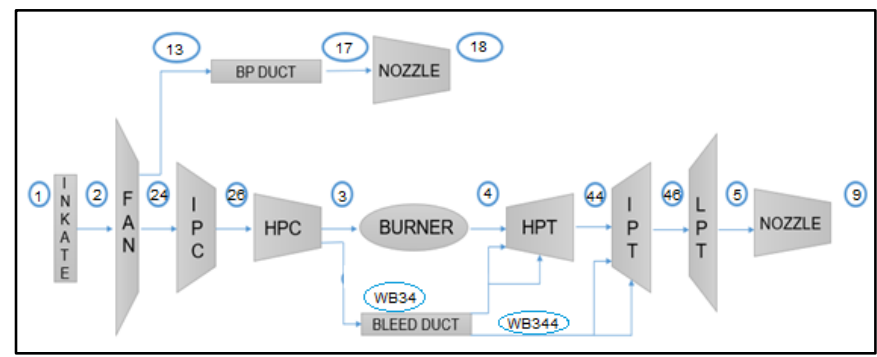

Figure 2: Engine Layout

A direct drive architecture was set-up, as shown in figure 2 , with the inbuilt weight estimation, cooling requirements and NOx emission models. The range and thrust requirements were chosen to coincide with that of a modern long-range civil aircraft, like A350-900.

Traditionally, engines are optimised for cruise so that they operate at/near peak efficiency for most of the mission. Following this, an off-design analysis is then performed at top of climb, to size the capacity of the engines which operate at their highest power setting. The take-off segment is run at offdesign to verify that enough cooling can be provided or that the blades can sustain the mission phase which has the highest TET. The design point, in this case, was selected to be the top of climb in order to provide a fair comparison against the baseline engine following the work performed by Dik et al in 2017. The authors aim at extending the latter's work by investigating the installed engine performance and the impact on NOx emission and mission block fuel burn.

Table 2 gives the thrust levels needed by each engine. Within the design process, it was ensured that the cruise and take-off requirements were met without exceeding material limitations while achieving cycle efficiency targets. The polytropic efficiency values were kept constant for the turbomachinery components at design point and were selected based on the work performed by Dik et al. and Alexiou et al. and listed in Table 3.

Table 2: Mission Requirements

\begin{tabular}{l|c|c|c}
\hline \hline & ToC & Cruise & TO \\
\hline \hline Net Thrust Requirements $(\mathrm{kN})$ & 69.4 & 53.38 & 283.6 \\
\hline Mach Number & 0.82 & 0.82 & 0 \\
\hline Altitute $(\mathrm{m})$ & 10668 & 10668 & 0 \\
\hline \hline
\end{tabular}

Table 3: Component Polytropic Efficiency at ToC

\begin{tabular}{l|c}
\hline Component & Polytropic Efficiency \\
\hline \hline Fan & 0.920 \\
\hline IPC & 0.906 \\
\hline HPC & 0.882 \\
\hline HPT & 0.918 \\
\hline IPT & 0.926 \\
\hline LPT & 0.939 \\
\hline \hline
\end{tabular}

\section{Baseline Engine Model}

The baseline engine model was replicated following the work performed by Dik et al in 2017 which specifies a typical configuration with EIS by 2010 . The design point chosen was a hot day (+10 K above ISA conditions) at top of climb. The polytropic efficiencies were kept constant and the engine specifications were summarised in Table 4.

Table 4: Baseline Engine Specifications at Design Point (Dik et. al., 2017)

\begin{tabular}{l|l|l|l}
\hline \hline Altitude & $10670 \mathrm{~m}$ & $\eta_{\text {poly,fan }}$ & 0.905 \\
\hline Mach & 0.82 & $\eta_{\text {poly,IPC }}$ & 0.921 \\
\hline Inlet Mach & 0.50 & $\eta_{\text {poly,HPC }}$ & 0.943 \\
\hline ISA & $+10 \mathrm{~K}$ & $\eta_{\text {poly,LPT }}$ & 0.906 \\
\hline Net Thrust & $69400 \mathrm{~N}$ & $\eta_{\text {poly,IPT }}$ & 0.898 \\
\hline Mass Flow & $490 \mathrm{~kg} / \mathrm{s}$ & $\eta_{\text {poly,HPT }}$ & 0.899 \\
\hline SFN & $142 \mathrm{N.s} / \mathrm{kg}$ & TET & $1440 \mathrm{~K}$ \\
\hline BPR & 6.7 & Fan Diameter & $2.93 \mathrm{~m}$ \\
\hline SFC & $15.3 \mathrm{~g} / \mathrm{kN} . \mathrm{s}$ & PR split exp & 0.478 \\
\hline OPR & 45 & FPR & 1.63 \\
\hline $\begin{array}{l}\text { Pressure } \\
\text { loss (intake, } \\
\text { duct) }\end{array}$ & $1 \%$ & $\begin{array}{l}\text { Pressure Loss } \\
\text { (combustor) }\end{array}$ & $5 \%$ \\
\hline $\begin{array}{l}\text { Fan Hub to } \\
\text { Tip Ratio }\end{array}$ & 0.3 & $\begin{array}{l}\text { Overall Cooling } \\
\text { (\% of Inlet Mass }\end{array}$ & 18 \\
\hline \hline
\end{tabular}

\section{Cooling Flow Model}

An empirical model was used for the determination of the cooling flow requirements which is a built-in feature within NPSS. Having as input the metal temperature and the cooling effectiveness, the amount of cooling is determined from the following equations. (Gauntner, 1980)

$$
\begin{gathered}
m_{\text {blade }}=F c \times 0.022 \times(P H I /(1-P H I))^{1.25} \times m_{m f} \\
P H I=\left(T_{h g}-T_{m}\right) /\left(T_{m}-T_{c f}\right) \\
P H I=\left(C_{\text {profile }}+P H I\right) /\left(C_{\text {profile }}+1\right) \\
T_{\text {hg }}=C \times T_{m f}+T_{\text {margin }} \\
m_{c f}=m_{\text {blade }} \times 4 / 3
\end{gathered}
$$

$F_{c}$ represents the cooling configuration. For instance, the default value of 1 was set to represent film cooling. This value can be modified to $2.0,1.5$ or 0.8 to model fully transpiration 
blade cooling, advanced convective cooling or convective cooling respectively (Esgar et al., 1970). A constant of 0.022 is used in equation 1 which is the coolant flow ratio used for full coverage film cooling which was obtained from experimental data (Livingood et al., 1971). PHI is used to represent the cooling effectiveness which is defined by the ratio of the difference between the hot gas temperature and the blade metal temperature to the difference between the metal temperature and the temperature of the cooling flow as shown in equation 2. It is corrected before being applied to equation 1 to account for the radial temperature profile of the combustor if it is an NGV. A factor of $4 / 3$ is then used to account for the amount of cooling flow for the end wall, shroud and leakage and obtain the total cooling flow required as shown in equation 5 .

\section{Weight Model}

Many models have been built to estimate the engine weight, while the majority of the models are only feasible for low bypass ratio engines. The model used in this project is based on the method created by Guha (2012). The bare engine length and mass can be described as a function of the fan diameter using equation 6 and 7. Mass flow continuity is used to calculate the fan inlet area with the assumption that the flow Mach number at the fan inlet is 0.5 at top of climb (Merchant and Arlington, 2010). The fan diameter is obtained by equation 9 (Vahdati and Cumpsty, 2016). It is used with the assumption that the fan hub-to-tip ratio is 0.3 for the baseline engine and 0.25 for a high BPR engine (Kaplan et al., 2006) as previously mentioned.

$$
\begin{gathered}
L_{\text {engine }}=1.81 \times D_{\text {fan }}-19.8 \\
m_{\text {engine }}=2.652 \times\left(L_{\text {engine }} \times D_{\text {fan }}{ }^{2}\right)^{0.5833} \\
\dot{m}=\rho V A \\
D_{\text {fan }}=\frac{4 \times A}{\pi\left(1-R_{h t}^{2}\right)}
\end{gathered}
$$

\section{NOx Emission Model}

Emission of Nitrogen Oxide gasses contribute to the production of the tropospheric greenhouse gas 'ozone' through the photochemical reaction in the atmosphere. NOx generation in combustors is mainly influenced by the flame temperature which is related to the OPR of the engine. However, a higher OPR improves thermal efficiency which has a direct impact on SFC and carbon emission. It is seen that a reduction in SFC is often traded-off by an increase in NOx emission. However due to the progress achieved by the research community and industry, combustors are ingeniously designed to prevent high flame temperatures. Such designs include RQL combustors, the injection of water or steam into the combustion zone, dry low NOx combustion (DLN) or even catalytic combustion which holds the promise of achieving very low emission levels.
Within the modelling, the empirical correlation for NOx emission is based on the work performed by NASA and derived from equation 10 (Daggett, 2004). It gives a NOx prediction aligning with current technological level.

$$
E I N O x=33.2 \times\left(\frac{P_{3}}{432.7}\right)^{0.4} \times e^{\left(\frac{\left(T_{3}-459.67-1027.6\right)}{349.9}+\frac{6.29-6.3}{53.2}\right)}
$$

$\mathrm{P}_{3}$ is the combustor inlet pressure in Psia and $\mathrm{T}_{3}$ is the combustor inlet temperature in Rankine. This correlation replicates the behaviour of GE90 and PW4000 types of engines. The accuracy of this model was validated against ICAO engine test data points during take-off and climb-out and against Boeing GE90-85B engine performance data (Daggett, 2004). It was shown that the model underpredicted NOx emission level by $7.4 \%$ at lower power settings (climbout) which is still reasonable for the purpose of this study.

\section{Design of Experiment}

Through the variation of four main design variables namely FPR, OPR, TET and specific thrust, optimum engine configurations which minimises SFC while achieving the thrust requirements at three flight phases are obtained. Through a multipoint design approach, which considers various flight phases and standard for aero-engine applications (Guha, 2001), the optimum point was obtained through a manual iteration process as shown in Figure 3 and elaborated in the subsequent section.

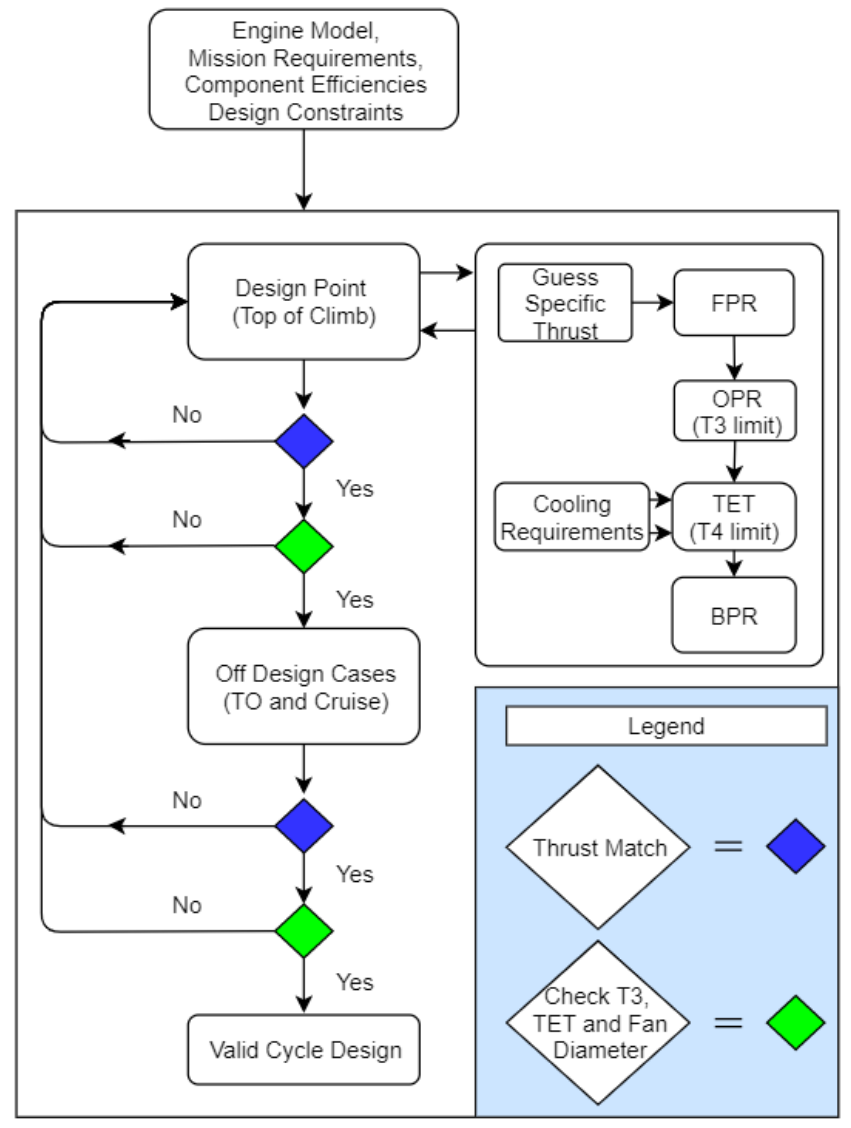

Figure 3: Design of Experiment 
The mission requirements (Table 2), component efficiencies (Table 3 and 4) and the design constraints (Table 1) are first established to restrict the design space. The design point of the engine was set up for minimum SFC. It was obtained through an iterative process which was initiated by guessing specific thrust which gives the optimum FPR, according to Guha (2001). The OPR was then chosen based on the material temperature limitations at the outlet of the HPC $\left(\mathrm{T}_{3}\right)$. The TET is then fixed by the T4 technological limiter for an NGV blade with thermal barrier coating and full coverage film cooling. The cooling requirements are calculated and fed back to the loop. A reasonable upper limit for the cooling requirements $(\sim 20 \%)$ were set so as to restrict further the design space to eliminate engine candidate with poor thermal efficiency due to excessive cooling. As a consequence of fixing all the prior design parameters, the BPR can be obtained.

Checks were made (illustrated by coloured prisms) to ensure that the thrust requirements were met and the engine were with the limits set. After the optimum design point was achieved, the same checks were performed for the off-design cases which in this case were the TO and Cruise. Following this, valid cycle designs were generated.

\section{Aircraft Model}

The aircraft model chosen for its long range and widebody configuration which is similar to the A350-900XWB. It reunites the latest technological advances due to its aerodynamic design, carbon fibre fuselage and wings. With a range of $18000 \mathrm{~km}$, it is considered as the main choice of longrange civil aircraft for the next decade and hence is a suitable candidate for this study.

The mission analysis was performed using the Flight Optimisation System (FLOPS) which is a multidisciplinary system of computer programs for conceptual and preliminary design and evaluation of advanced aircraft concepts developed by NASA. A standard mission profile was selected for a longrange flight which consists of the climb phase $(280 \mathrm{~km})$, cruise $(12400 \mathrm{~km})$ and descent $(280 \mathrm{~km} \mathrm{~nm})$ over a total range of $13000 \mathrm{~km}$.

\section{RESULTS AND DISCUSSION}

\section{Engine Results}

Following the engine design process, an approximation to the SFC optimum Pareto front was obtained to cover the design space of the engine, as shown in Figure 4. It defines the boundary between specific thrust and SFC which can be obtained through the variation of engine design parameters. The frontier for the baseline engine with EIS 2010 is expected to be a translation of this curve towards increasing SFC, as shown by the dotted line (for illustrative purposes only). With the updated technological limiters, this frontier was pushed and this allowed for an engine with the same specific thrust to achieve a better SFC.

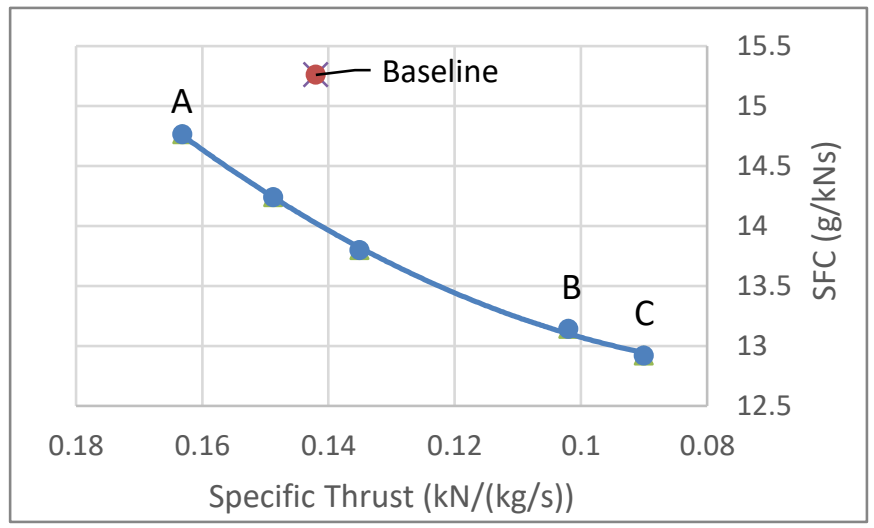

\section{Figure 4: Boundary between specific thrust and SFC}

Three engine designs, located on the Pareto front and covering a wide range of the curve, were selected for the mission analysis and comparison against the baseline engine. The results are summarised in Table 5 .

Engine design $\mathrm{C}$ showed the highest improvement in SFC with a reduction of about $15 \%$. This is mainly due to the decrease in specific thrust by $36 \%$. This is also shown by the behaviour of the BPR which increased by a multiple of 3.3 and by the propulsive efficiency which improved by $3.4 \%$. On the downside, this increase in propulsive efficiency was accompanied by a $24 \%$ increase in fan diameter and a $48 \%$ increase in engine weight. The OPR for all three designs exceeded 50 which is a $30 \%$ improvement from the baseline engine while the TET improved by $200 \mathrm{~K}$.

Considering the trend from Engine A to $\mathrm{C}$, as the BPR increases, the propulsive efficiency also increased (3\% increment for engine $\mathrm{C}$ compared to $\mathrm{A})$. The thermal efficiency of engine A varied significantly compared to B and $\mathrm{C}$ due to the comparatively low OPR (12\% difference relative to engine B) while the TET varied by little across the engines. For instance, despite having a higher TET, the thermal efficiency of engine $C$ was slightly lower than that of engine $\mathrm{B}$ due to the lower OPR. The transfer efficiency deteriorated slightly with the increase in BPR. Nevertheless, due to the dominance of the propulsive efficiency, the overall efficiency was improved with increasing BPR and so did SFC.

Table 5: Design Parameters at ToC

\begin{tabular}{l|c|c|c|c}
\hline \hline & Baseline & $\mathrm{A}$ & $\mathrm{B}$ & $\mathrm{C}$ \\
\hline \hline OPR & 45.0 & 53.5 & 59.3 & 57.2 \\
\hline $\mathrm{BPR}$ & 6.7 & 10.0 & 18.0 & 22.0 \\
\hline $\mathrm{TET}$ & 1440 & 1805 & 1770 & 1811 \\
\hline FPR & 1.63 & 1.76 & 1.44 & 1.39 \\
\hline $\boldsymbol{\eta}_{\boldsymbol{T h}}$ & 0.437 & 0.450 & 0.501 & 0.499 \\
\hline $\boldsymbol{\eta}_{\boldsymbol{T R}}$ & 0.840 & 0.875 & 0.870 & 0.869 \\
\hline $\boldsymbol{\eta}_{\boldsymbol{p r o p}}$ & 0.872 & 0.874 & 0.883 & 0.902 \\
\hline $\boldsymbol{\eta}_{\boldsymbol{O}}$ & 0.320 & 0.344 & 0.385 & 0.391 \\
\hline $\begin{array}{l}\mathrm{SFC} \\
\left(\mathrm{g} / \mathrm{kN} *^{\mathrm{sec}}\right)\end{array}$ & 15.26 & 14.77 & 13.14 & 12.92 \\
\hline
\end{tabular}




\begin{tabular}{l|c|c|c|c}
\hline $\begin{array}{l}\text { Net Thrust } \\
(\mathrm{kN})\end{array}$ & 69.56 & 69.57 & 69.40 & 70.29 \\
\hline $\begin{array}{l}\text { Specific } \\
\text { Thrust } \\
(\mathrm{kN} /(\mathrm{kg} / \mathrm{s}))\end{array}$ & 0.1420 & 0.1632 & 0.1020 & 0.0896 \\
\hline $\begin{array}{l}\text { Total } \\
\text { Cooling }\end{array}$ & 18.0 & 15.5 & 13.3 & 14.5 \\
Flow (\%) & 3.12 & 2.87 & 3.63 & 3.89 \\
\hline $\begin{array}{l}\text { Fan } \\
\text { Diameter } \\
(\mathrm{m})\end{array}$ & 7307 & 6272 & 9564 & 10871 \\
\hline $\begin{array}{l}\text { Engine } \\
\text { Weight }(\mathrm{kg})\end{array}$ & & &
\end{tabular}

Considering Design B as a suitable compromise between SFC and specific thrust, it is chosen as the most adequate candidate to compared against the baseline engine.

Engine B has a $28 \%$ reduction in specific thrust which led to a $16 \%$ increase in fan diameter and a $30 \%$ increment in engine weight. Due to the higher value of the hub-to-tip ratio of the baseline engine (0.3) compared to the new designs (value of 0.25 ), the latter benefited from a smaller fan diameter than expected. This is one of the reasons why engine $\mathrm{A}$ has a smaller diameter compared to the baseline engine despite having a higher BPR. In addition to this, the higher OPR, reduced the size of the core which contributed to the reduced of the fan size despite the small increase in BPR.

An optimum BPR for Design B at the design point (ToC) was 18 which is almost three times larger than the BPR (6.8) of the baseline engine. This increase in BPR resulted in a much lower FPR value (1.44) and an improved propulsive efficiency value (0.883). Referring to table A2, within the Appendix, the maximum BPR for the new design approached a value of 20 at cruise condition and the value of FPR was 1.361. As a result, propulsion efficiency increased by $13.32 \%$. The fan diameter for Design B increased by $16 \%$ compared to the baseline engine, resulting in a $31 \%$ increase of the total engine weight. The maximum temperature of the high pressure compressor exit was $916.21 \mathrm{~K}$ at take-off which gave a $80 \mathrm{~K}$ margin to the limit temperature.

For an improved thermal efficiency, TET is a crucial parameter. The maximum TET at take-off condition is $1850 \mathrm{~K}$, which is more than $300 \mathrm{~K}$ above the baseline engine. An important consideration which accompanies an increase TET is the cooling flow requirements. According to the cooling model calculation, only $8.6 \%$ of the cooling flow was needed to be extracted from the HPC exit to achieve the required metal temperature for the HPT vanes and blades and $4.7 \%$ for the LPT vanes and blades at the take-off point. At the cruise condition, the TET obtained was $1620 \mathrm{~K}$ in order to meet the net thrust requirement. This was only $220 \mathrm{~K}$ higher than the metal limit temperature (1400K). This gives a high margin of protection pertaining to the HPT vanes at cruise condition. By choosing the optimum values for the four critical parameters, the new engine design achieved a reduction in SFC for all three operating points. At cruise condition, the SFC for new design engine achieved a $13.92 \%$ improvement compared to that of the baseline engine.
However, the uninstalled performance of an engine cannot, in itself, give a clear indication of the effects of having a bigger fan diameter or engine weight on fuel saving potential. Hence, a mission analysis was performed.

\section{Mission Analysis}

Following the design of the engine, through an improvement in propulsive efficiency, reductions in SFC were achieved. However, this resulted in a larger fan diameter. After installation, the engine needs to maintain a suitable distance above the tarmac to avoid scraping or ingestion of debris. Considering an A350-900 XWB engine, whose fan diameter is $3.17 \mathrm{~m}$, the ground clearance was $0.72 \mathrm{~m}$ (Airbus, 2019). Table 5 shows the fan diameters of the baseline engine and new engine designs. When considering similar nacelle thickness and technological levels, the ground clearance was negative for Design $\mathrm{C}$ which was too large to fit under the wing. As for design $B$, the engine ground clearance was about $0.27 \mathrm{~m}$. However, with current progress achieved in nacelle development, in terms of length and thickness, engine B can be fitted while maintaining the requirements in terms of ground clearance.

\section{Block Fuel Burn}

The mission fuel burn study was based on the former cycle with $7000 \mathrm{~nm}$ range. The fuel burn calculation was carried out by using FLOPS.

The block fuel for each engine was shown in Table 6 . Compared to the NPSS calculation result, the optimum block fuel performance was achieved with Design B, with a reduction of $15 \%$ in terms of fuel consumption. For Design A, the block fuel decreased by $6.84 \%$ to the baseline engine. Although Design C had the best SFC performance at the three main design conditions, the block fuel was higher than Design $B$ due to the larger weight and size.

Table 6: Comparison in Block Fuel Burn

\begin{tabular}{l|c|c}
\hline \hline & Block Fuel (kg) & Change \\
\hline \hline Baseline & 92143 & - \\
\hline Design A & 85844 & $-6.84 \%$ \\
\hline Design B & 78495 & $-14.81 \%$ \\
\hline Design C & 81356 & $-11.71 \%$ \\
\hline
\end{tabular}

\section{NOx Emission}

For a mission cycle, the engine worked at the maximum power setting for the climb segment, while a negligible amount of power was generated during the descent segment. Although the value of thrust varied throughout the cruise segment due to the gradual reduction in the weight of the aircraft as fuel was consumed, the change was small. NOx emission was only calculated within the climb and cruise segments for simplification. Within the climb segment, NOx emission used the data from the $\mathrm{ToC}$ calculation result, and the number in the cruise segment used the data from cruise calculation and presented in table 7 . 
Although the block fuel consumption was less than the baseline engine, the NOx emission values for new engine designs were higher. For instance, design B had a $29 \%$ increase in emission compared to the baseline. However, because the NOx emission model for the baseline and the engine designs assumed similar technology levels, an improvement was not seen due to the high firing temperature within the combustor. Nevertheless, it gives a reasonable estimate as to the extent NOx emission is increased.

Table 7: Comparison in NOx Emission

\begin{tabular}{|c|c|c|c|c|c|}
\hline & & \multirow{2}{*}{$\begin{array}{c}\text { Fuel } \\
\text { Mass } \\
(\mathrm{kg})\end{array}$} & \multirow{2}{*}{$\begin{array}{c}\text { NOx } \\
\text { Emission } \\
(\mathrm{kg}) \\
\end{array}$} & \multicolumn{2}{|c|}{ Total Emission } \\
\hline & & & & $\mathrm{kg}$ & $\%$ \\
\hline \multirow{2}{*}{ Baseline } & Climb & 8532 & 164.73 & \multirow{2}{*}{1385.20} & \multirow{2}{*}{0} \\
\hline & Cruise & 85151 & 1220.46 & & \\
\hline \multirow{2}{*}{$\begin{array}{c}\text { Design } \\
\text { A }\end{array}$} & Climb & 8389 & 237.6 & \multirow{2}{*}{1783.50} & \multirow{2}{*}{+28.7} \\
\hline & Cruise & 78724 & 1545.9 & & \\
\hline \multirow{2}{*}{$\begin{array}{c}\text { Design } \\
\text { B }\end{array}$} & Climb & 7134 & 237.26 & \multirow{2}{*}{1943.75} & \multirow{2}{*}{+40.3} \\
\hline & Cruise & 72635 & 1706.48 & & \\
\hline \multirow{2}{*}{$\begin{array}{c}\text { Design } \\
\mathrm{C}\end{array}$} & Climb & 7389 & 232.11 & \multirow{2}{*}{1984.73} & \multirow{2}{*}{+43.3} \\
\hline & Cruise & 75239 & 1752.61 & & \\
\hline
\end{tabular}

\section{CONCLUSIONS}

In this project, a three-shaft turbofan engine model was built for an EIS 2025. The design process included considerations in terms of cooling flow, engine weight and NOx emission. Four main design parameters were varied namely: Specific thrust, FPR, OPR and TET. The DoE was set-up in order to down-select 3 suitable engine configurations that can illustrate the effect of cycle design variations on engine and aircraft fuel efficiency. The method didn't include the use of any design optimisation platforms. Its purpose was mainly to deliver a top level assessment and illustration of the magnitude of the performance improvement that can be achieved by the direct drive turbofan architecture. After the mission analysis it was found that with current improvements in material and aerodynamic design, a $13.92 \%$ reduction in SFC was achieved at cruise conditions. Furthermore, for a $7000 \mathrm{~nm}$ mission cycle, a significant reduction of $14.81 \%$ of the block fuel could be achieved.

The main technological advancements which allowed such progress to be achieved were summarised below:

1. Advanced, thinner and shorter nacelles are being designed for reduced weight and drag. Their close coupling with the fan allows for higher BPR and ground clearance requirements to be achieved.

2. Higher TET and HP compressor exit temperatures can be achieved which improves thermal efficiency due to current progress achieved in single crystal casting, thermal barrier coatings and cooling.

3. However, with an increase in OPR and TET, NOx emission increased. This behaviour does not replicate current progress made in combustor design and hence are very pessimistic. Nevertheless, it gives an overview of the extent to which NOx emission is increased and as to the feasibility of curtailing it with current technology.

4. The reduction in the fan hub-to-tip ratio enabled for a higher inlet area at the same fan tip diameter. Thus, the engine design can move to lower specific thrust values for the same fan diameter and improve the propulsive benefit.

Despite the new engine design larger fan diameter and weight, $16.11 \%$ and $30.9 \%$ respectively, due to the reduction in SFC, the overall fuel weight was reduced resulting in overall aircraft weight reduction. Nevertheless, since all engine designs used the same thrust requirements, the resulted fuel burn outputs represent the scenario of retrofitting new powerplants on already existing aircraft with a mission starting always at maximum aircraft ramp weight.

Further work planned for the present research focuses on four different elements. Initially, increased fidelity models for the engine cycle and structures will be applied. Then, a stirredreactor combustor model from Cranfield University (HEPHAESTUS) is planned to be used to allow the calculation of NOx as well as $\mathrm{CO} 2$ and $\mathrm{CO}$ emissions indexes (Prakash, 2015). Additions regarding aircraft/engine integration effects on the aircraft performance will be included while the flight mission will be setup to start at maximum payload and fuel. Finally, following the advances on highly integrated computational platforms, Cranfield University concept TERA (Techno-economic, Environmental \& Risk Assessment (Nalianda 2015), is planned to be applied in order to perform an overall engine design optimisation on direct operating cost as well as a technology investment analysis.

\section{AKNOWLEDGMENTS}

The authors wish to thank the Southwest Research Institute for providing the NPSS software.

$\begin{array}{ll}\text { ABBREVIATIONS } \\ \text { BPR } & \text { Bypass Ratio } \\ \text { EIS } & \text { Entry-into-service } \\ \text { FAR } & \text { Fuel-to-air ratio } \\ \text { FPR } & \text { Fan Pressure Ratio } \\ \text { GHG } & \text { Greenhouse gas } \\ \text { HP } & \text { High Pressure } \\ \text { HPC } & \text { High pressure compressor } \\ \text { HPT } & \text { High pressure turbine } \\ \text { IPC } & \text { Intermediate pressure compressor } \\ \text { IPT } & \text { Intermediate pressure turbine } \\ \text { LPC } & \text { Low pressure compressor } \\ \text { LPT } & \text { Low pressure turbine } \\ \text { NPSS } & \text { Numerical Propulsion System Simulation } \\ \text { OPR } & \text { Overall pressure ratio } \\ \text { SFC } & \text { Specific fuel consumption } \\ \text { TET } & \text { Turbine entry temperature } \\ \text { TO } & \text { Take-off } \\ \text { ToC } & \text { Top of Climb }\end{array}$




\section{NOMENCLATURE}

$\begin{array}{ll}C_{\text {profile }} & \text { Coefficient of hot gas } \\ D_{\text {fan }} & \text { Fan diameter } \\ \text { EINOx } & \text { NOx emission } \\ F C & \text { Constant for different cooling } \\ & \text { configuration } \\ L_{\text {engine }} & \text { Engine length } \\ m_{\text {blade }} & \text { Cooling flow for blade } \\ m_{\text {cf }} & \text { Total cooling flow } \\ m_{\text {engine }} & \text { Engine mass } \\ m_{m f} & \text { Main flow } \\ P_{3} & \text { Combustor inlet pressure } \\ P H I & \text { Cooling Effectiveness } \\ T_{3} & \text { Combustor inlet temperature } \\ T_{c f} & \text { Cooling flow temperature } \\ T_{h,} & \text { Hot gas temperature } \\ T_{m} & \text { Blade metal temperature } \\ \eta_{O} & \text { Overall efficiency } \\ \eta_{\text {prop }} & \text { Propulsion efficiency } \\ \eta_{T h} & \text { Thermal efficiency } \\ \eta_{T R} & \text { Transfer efficiency }\end{array}$

\section{REFERENCES}

Airbus (2019) 'Aircraft Characteristics Airport and Maintenance Planning', Airbus S.A.S., pp. 1-387

Alexiou, A., Aretakis, N., Roumeliotis, I., Kolias, I. and Mathioudakis, K. (2017) Performance Modelling of an Ultra high bypass ratio geared turbofan, ISABE.

Daggett, D. L. (2004) 'Water misting and injection of commercial aircraft engines to reduce airport NOx', National Aeronautics and Space Administration Glenn. Available at: http://publication/uuid/E2E86729-40A2-4221-AE66-

\section{BC427DD83232}

Dik, A., Bitén, N., Zaccaria, V., Aslanidou, I. and Kyprianidis, K. G. (2017). Conceptual Design of a 3-Shaft Turbofan Engine with Reduced Fuel Consumption for 2025, Energy Procedia. Elsevier B.V., 142, pp. 1728-1735. doi: 10.1016/j.egypro.2017.12.556

Esgar, J. B., Colladay, R. S. and Kaufman, A. (1970) 'An analysis of the capabilities and limitaions of turbine are cooling method', NASA Technical Memorandum

European Commission (2001) European Aeronautics: A Vision for 2020, Office for Official Publications of the European Communities, Luxembourg, ISBN 92-894-0559-7.

Gauntner, J. W. (1980) 'Algorithm for Calculating Turbine Cooling Flow and the Resulting Decrease in Turbine Efficiency', NASA Technical Memorandum, 81453.

Guha, A., Boylan, D. and Gallagher, P. (2012) 'Determination of optimum specific thrust for civil aero gas turbine engines: a multidisciplinary design synthesis and optimisation', 227(3), pp. 502-527. doi: 10.1177/0954410011435623.

Guha, A. (2001) 'Optimisation of aero gas turbine engines' The aeronautical journal of the royal aeronautical society.
Heikurinen, Karl and Townsend, Peter (2017) 'Low hub-to-tip ratio fan for a turbofan gas turbine engine' United States PRATT \& WHITNEY CANADA CORP. (Longueuil, CA) 20170268529. [Online] Available at : http://www.freepatentsonline.com/y2017/0268529.h htm [Accessed at: $8^{\text {th }}$ August 2019]

Kaplan, B., Nicke, E. and Voss, C. (2006) 'Design of A highly Efficient Low-Noise Fan for Ultra-high Bypass Engines', pp. 1-8

Korsia J-J. VITAL (2009), European R\&D Programme for Greener Aero-Engines. ISABE-2009-1114. Proceedings of the $19^{\text {th }}$ International Symposium on Air Breathing Engines, Montreal.

Lagow, B.W. (2016), Materials Selection in Gas Turbine Engine Design and the Role of Low Thermal Expansion Materials. JOM 68, https://doi.org/10.1007/s11837-016-2071-2

Livingood, J. N. B., Ellerbrock, H. H. and Kaufman, A. (1971) Nasa Turbine Cooling Research Status Report, [Online] Available

at: https://ntrs.nasa.gov/archive/nasa/casi.ntrs.nasa.gov/1971002 6644.pdf [Accessed: 15 August 2019]

Merchant, A. and Arlington (2010) 'Jet Engine Inlet-Fan System and Design Method'

Pitt I. L., J.R. Norsworthy, (1999) 'Economic of the U.S. Commercial Airline Industry: Productivity Technology and Deregulation' Kluwer Academic Publishers. pp. 48.

Rolt A. and Whurr J. (2015) 'Optimizing Propulsive Efficiency in Aircraft with Boundary Layer Ingesting Distributed Propulsion'

Sauer, T., Ruckel T. and Peitsch D. (2019) 'Development of a flight mission model and its application in order to illustrate the influence of variable thrust nozzles', doi: 10.33737/gpps19-bj-217.

Safran (2020) 'Gulfstream's G700 goes airborne with Safran Nacelles' newest nacelle for large-cabin business jets'. [Online] Available at: https://www.safrannacelles.com/media/gulfstreams-g700-goes-airborne-safrannacelles-newest-nacelle-large-cabin-business-jets-20200214 [Accessed: 25 March 2020]

Southwest Research Institute (2016), Numerical Propulsion System Simulation (NPSS), [Online] Available at: https://www.swri.org/consortia/numerical-propulsionsystem-simulation-npss [Accessed: 15 August 2019]

Vahdati, M. and Cumpsty, N. (2016) 'Aeroelastic Instability in Transonic Fans', Journal of Engineering for Gas Turbines and Power, 138(2), pp. 1-14. doi: 10.1115/1.4031225.

Walsh P.P. and Fletcher P. (2004) 'Gas Turbine Performance' Blackwell Science Ltd.

Prakash, A., (2015) 'Prediction of NOx Emissions for an RQL Combustor using a Stirred Reactor Modelling Approach', PhD Thesis, Cranfield University, UK.

Nalianda, D.K, Kyprianidis K.G., Sethi V. and Singh R., (2015) "Techno-economic viability assessments of novel propulsion technology under potential environmental regulatory policy scenarios", Elsevier, Applied Energy, Vol. 157, pp. 35-50, DOI: 10.1016/j.apenergy.2015.07.017. 
APPENDIX A - COPYRIGHT/OPEN ACCESS

Table A1: Design Parameters of Engine A

\begin{tabular}{|l|c|c|c|}
\hline Parameter & ToC & Cruise & $\begin{array}{l}\text { Take- } \\
\text { Off }\end{array}$ \\
\hline Fan PR & 1.76 & 1.626 & 1.71 \\
\hline IP Comp PR & 8 & 7.3 & 7.8 \\
\hline HP Comp PR & 3.8 & 3.67 & 3.71 \\
\hline HP Turb PR & 2.1 & 2.10 & 2.1 \\
\hline IP Turb PR & 2.13 & 2.15 & 2.14 \\
\hline LP Turb PR & 6.67 & 6.66 & 6.48 \\
\hline Temp at exit of HP Comp & 827.9 & 772.4 & 919.5 \\
\hline TET(K) & 1805.5 & 1638.8 & 1972.2 \\
\hline BPR & 10 & 10.9 & 10.2 \\
\hline OPR & 53.5 & 43.7 & 49.4 \\
\hline MassFlow (kg/sec) & 426.3 & 396.6 & 1046.2 \\
\hline $\boldsymbol{\eta}_{\boldsymbol{T} h}$ & 0.45 & 0.47 & 0.491 \\
\hline $\boldsymbol{\eta}_{\boldsymbol{T}}$ & 0.875 & 0.897 & 0.892 \\
\hline $\boldsymbol{\eta}_{\boldsymbol{p r o p}}$ & 0.874 & 0.878 & \\
\hline $\boldsymbol{\eta}_{\boldsymbol{O}}$ & 0.393 & 0.413 & \\
\hline SFC(g/(kN*sec)) & 14.766 & 14.091 & 8.065 \\
\hline NetThrust(kN) & 69.574 & 54.045 & 340.178 \\
\hline SpecificThrust(kN/(kg/s)) & 0.1632 & 0.1363 & 0.3251 \\
\hline TotalCoolingFlow(\%) & \multicolumn{3}{|c|}{15.5} \\
\hline FanDiameter(m) & \multicolumn{5}{|c|}{6272.9} \\
\hline EngineWeight(kg) & \multicolumn{5}{|l}{} \\
\hline \hline
\end{tabular}

Table A2: Design Parameters of Engine B

\begin{tabular}{|l|c|c|c|}
\hline \hline Parameter & ToC & Cruise & $\begin{array}{l}\text { Take- } \\
\text { Off }\end{array}$ \\
\hline Fan PR & 1.44 & 1.361 & 1.36 \\
\hline IP Comp PR & 9.8 & 8.871 & 8.972 \\
\hline HP Comp PR & 4.2 & 4.07 & 4.023 \\
\hline HP Turb PR & 2.252 & 2.263 & 2.253 \\
\hline IP Turb PR & 2.288 & 2.299 & 2.298 \\
\hline LP Turb PR & 9.19 & 8.919 & 7.202 \\
\hline Temp at exit of HP Comp & 851.19 & 798.21 & 916.21 \\
\hline TET(K) & 1770 & 1620 & 1850 \\
\hline BPR & 18 & 19.77 & 17.55 \\
\hline OPR & 59.27 & 49.14 & 49.11 \\
\hline Masslow (kg/sec) & 680.39 & 646.41 & 1468.7 \\
\hline $\boldsymbol{\eta}_{\boldsymbol{T}}$ & 0.501 & 0.502 & 0.459 \\
\hline $\boldsymbol{\eta}_{\boldsymbol{T}}$ & 0.87 & 0.892 & 0.858 \\
\hline $\boldsymbol{\eta}_{\boldsymbol{p r o p}}$ & 0.883 & 0.904 & \\
\hline $\boldsymbol{\eta}_{\boldsymbol{O}}$ & 0.442 & 0.453 & \\
\hline SFC(g/(kN*sec)) & 13.141 & 12.796 & 6.086 \\
\hline NetThrust(kN) & 69.396 & 53.983 & 342.096 \\
\hline SpecificThrust(kN/(kg/s)) & 0.1020 & 0.0835 & 0.2329 \\
\hline TotalCoolingFlow(\%) & \multicolumn{3}{|c|}{13.3} \\
\hline FanDiameter(m) & \multicolumn{3}{|c|}{9.626} \\
\hline EngineWeight(kg) & \multicolumn{3}{|l}{} \\
\hline
\end{tabular}

Table A3: Design Parameters of Engine C

\begin{tabular}{|l|c|c|c|}
\hline Parameter & ToC & Cruise & $\begin{array}{l}\text { Take- } \\
\text { Off }\end{array}$ \\
\hline Fan PR & 1.39 & 1.326 & 1.307 \\
\hline IP Comp PR & 9.8 & 8.984 & 8.836 \\
\hline HP Comp PR & 4.2 & 4.089 & 4.012 \\
\hline HP Turb PR & 2.209 & 2.218 & 2.211 \\
\hline IP Turb PR & 2.228 & 2.235 & 2.232 \\
\hline LP Turb PR & 10.867 & 10.256 & 7.606 \\
\hline Temp at exit of HP Comp & 842.9 & 797.2 & 902.2 \\
\hline TET(K) & 1811.1 & 1677.8 & 1877.8 \\
\hline BPR & 22 & 23.9 & 20.0 \\
\hline OPR & 57.2 & 48.7 & 46.3 \\
\hline MassFlow (kg/sec) & 784.7 & 752.3 & 1620.4 \\
\hline $\boldsymbol{\eta}_{\boldsymbol{T} \boldsymbol{h}}$ & 0.499 & 0.503 & 0.442 \\
\hline $\boldsymbol{\eta}_{\boldsymbol{T R}}$ & 0.869 & 0.889 & 0.839 \\
\hline $\boldsymbol{\eta}_{\boldsymbol{p r o p}}$ & 0.902 & 0.91 & \\
\hline $\boldsymbol{\eta}_{\boldsymbol{O}}$ & 0.450 & 0.458 & \\
\hline SFC(g/(kN*sec) $)$ & 12.915 & 12.679 & 5.796 \\
\hline NetThrust(kN) & 70.294 & 56.46 & 347.228 \\
\hline SpecificThrust(kN/(kg/s)) & 0.0896 & 0.0750 & 0.2143 \\
\hline TotalCoolingFlow(\%) & \multicolumn{4}{|c|}{14.5} \\
\hline FanDiameter(m) & \multicolumn{3}{|c|}{10871.7} \\
\hline EngineWeight(kg) & \multicolumn{5}{|c|}{} \\
\hline
\end{tabular}

